\title{
Paediatric asthma outpatient care by asthma nurse, paediatrician or general practitioner: randomised controlled trial with two-year follow-up
}

\author{
*Maarten Kuethe ${ }^{a}$, Anja Vaessen-Verberne ${ }^{a}$, Paul Mulder ${ }^{b}$, Patrick Bindelsc, Wim van Aalderen ${ }^{d}$ \\ a Department of Paediatrics, Amphia Hospital, Breda, Noord Brabant, The Netherlands \\ ${ }^{b}$ Department of Biostatistics, ErasmusMC, Rotterdam, The Netherlands \\ ' Department of General Practice, ErasmusMC, Rotterdam, The Netherlands \\ ${ }^{\mathrm{d}}$ Department of Paediatric Respiratory Medicine, Academical Medical Centre, Amsterdam, The Netherlands
}

Received 26th July 2010; revised 28th September 2010; accepted 12th November 2010; online 10th February 2011

\begin{abstract}
Aims: For children with stable asthma, to test non-inferiority of care provided by a hospital-based specialised asthma nurse versus a general practitioner (GP) or paediatrician.

Methods: Randomised controlled trial evaluating standard care by a GP, paediatrician or an asthma nurse, with two-year follow-up.

Results: 107 children were recruited, 45 from general practice and 62 from hospital. After two years, no significant differences between groups were found for airway responsiveness, FEV 1 , asthma control, medication, school absence or parental work absence. In the general practice group there was a significantly lower frequency of regular review visits ('regular' = at least one review per six months) compared to the paediatrician and specialised asthma nurse group, both after one year [45.7\% versus $87.9 \%$ and $94.3 \%$, respectively, $(p<0.0005)$ ] and after two years [26.5\% versus $87.9 \%$ and $75.8 \%$, respectively, $(p<0.0005)]$. We found no significant differences in unplanned visits. In most cases the asthma nurse was able to provide care without consultation with the paediatrician.

Conclusion: The degree of disease control in stable childhood asthma managed by an asthma nurse is not inferior to traditional management by primary or secondary care physicians. The results also suggest that a lower review frequency does not detract from good disease control.

(C) 2011 Primary Care Respiratory Society UK. All rights reserved.

MC Kuethe et al. Prim Care Respir J 2011; 20(1): 84-91

doi:10.4104/pcrj.2011.00003
\end{abstract}

Keywords asthma, paediatrics, management, economics, nurse, chronic care, GP, specialist nurse, RCT

See linked editorial by Haughney on page 9

The full version of this paper, with online Appendices 1

and 2 , is available at www.thepcrj.org

\section{Introduction}

Asthma is the most common chronic disease in childhood. ${ }^{1}$ Its high prevalence puts a considerable burden on health care resources, and effective asthma management is important to reduce morbidity and to optimise utilisation of health care facilities. This has led to the development of guidelines for asthma diagnosis and management. ${ }^{2-5}$ It is commonly agreed that the pharmaceutical cornerstone of asthma management in children is treatment with an inhaled corticosteroid (ICS) ${ }^{6,7}$ However, to achieve good control, regular follow-up is considered of the utmost importance. This follow-up should include assessment of asthma control status, comprehensive patient education, institution of (inhaled) medication and instructions on inhalation technique, implementation of a selfmanagement plan, and regular medical review. ${ }^{8-10}$ Until recently these aspects of care were provided by physicians only. However, these steps are time consuming, and specialised asthma nurses are now widely employed in this setting.

Over the last few decades there has been a considerable increase in the prevalence of asthma leading to an increased number of children requiring asthma management in general

\footnotetext{
* Corresponding author: Dr Maarten Christiaan Kuethe, Department of Paediatrics, Amphia Hospital, PO Box 90157, Breda, Noord Brabant 4800RL The Netherlands. Tel: 0031765954228 Fax: 0031765952387 E-mail: mkuethe@amphia.nl
} 
practice and in hospital..$^{11,12}$ This places a stress on the limited available manpower in primary and secondary care settings, and many general practitioners (GPs) as well as paediatricians lack sufficient time for this comprehensive care. Furthermore, the socalled "chronic care model"13-15 has not yet been widely implemented in many hospitals and general practices, indicating that the routing of acute and chronic care is not separate hence, acute care can tend to impinge upon the time for chronic care of children with asthma.

We assumed, based on earlier research, ${ }^{16,17}$ that an asthma nurse is able to provide good asthma care by reinforcing knowledge, ensuring adherence to a management plan, checking inhalation technique, and adjusting medication according to guidelines. Therefore we formulated the hypothesis that asthma management provided by a hospital-based specialised asthma nurse is not inferior to management provided by a GP or a paediatrician. The aim of this study was to test this hypothesis.

\section{Methods}

\section{Patients}

We recruited children with moderate and stable asthma from the outpatient department of a large general hospital and from $18 \mathrm{GPs}$ in the same region. All selected GPs had a special interest in paediatric asthma. Patients from primary care were selected by evaluating electronic patient files. The selection was based on a doctor's diagnosis of asthma, use of ICS and age limits, and an ensuing short telephone interview. Children fulfilling the criteria for moderate asthma as defined by the relevant Dutch guideline (NHG standaard astma bij kinderen ${ }^{18}$ ) and who were on continuous use of ICS were invited to participate. Patients in hospital care were treated by two paediatric pulmonologists.

During consecutive follow-up visits children aged 6-16 years with moderate asthma according to the National Guidelines of the Dutch Paediatric Pulmonologists, who used ICS for at least 9 months prior to the study, were assessed. ${ }^{4,5}$ Children with severe asthma defined according to the Asthma Guidelines of the Dutch Paediatric Association ${ }^{5}$ were excluded (step 4, unstable asthma despite treatment with high dose ICS and the addition of long-acting $\beta_{2}$-agonists (LABA/ICS) and/or montelukast). Furthermore, children who were not able to perform lung function tests and those with other chronic diseases were excluded.

\section{Study design}

Children were allocated to one of three follow-up arms follow-up by a GP, a paediatrician (PP), or a hospital-based specialist asthma nurse (AN) - for a period of two years. Sealed numbered envelopes with designated follow-up arms, based on a randomised computer-generated list, were used. Randomisation was stratified by type of treating physician before recruitment. The asthma nurse worked strictly according to the guidelines of the Dutch Paediatric Association and could count on consultant support from one of the paediatricians at any time. Written informed consent was obtained from all parents and from patients aged 12 years and older. The study protocol was approved by the Medical Ethics Committee.

Children were followed-up for two years on the basis of usual care. At randomisation, and after one and two years, lung function measurements were performed. In addition, data on exacerbations, school absence, parental absence from work, asthma control status and use of medication were collected. $\mathrm{PD}_{20}$ (the provocative dose of methacholine causing a $20 \%$ fall in forced expiratory volume in one second $\left[\mathrm{FEV}_{1}\right]$ from baseline) was chosen as the primary outcome measure, since at the time of study design (2004) there was considerable emphasis on airway hyper-responsiveness ${ }^{19,20}$ as a key feature of asthma control. When we started the study in 2006 the concept of asthma 'control' was not yet fashionable, and drug treatment decisions were based on disease 'severity' rather than disease control.

A non-inferiority design was chosen, where non-inferiority was defined as an expected $\mathrm{PD}_{20}$ in the AN-group not dropping by more than one doubling dose unit (DD-unit) below that in either of the other groups. Assuming a standard deviation for $\mathrm{PD}_{20}$ of 1.2 DD-unit ${ }^{21}$ and using a one-sided significance level of 0.027 per comparison (Dunnett's correction), the number of subjects needed to detect noninferiority with $90 \%$ power is 32 per group.

\section{Lung function tests}

Measurements were performed when children were in a stable condition. Short-acting $\beta_{2}$-agonists were stopped for 8 hours and long-acting $\beta_{2}$-agonists for 36 hours before each visit. Lung function testing included spirometry, measurement of $\mathrm{PD}_{20}$ methacholine, and the fraction of exhaled nitric oxide (FENO). FEV 1 was measured with a Master screen electronic spirometer (Jaeger, Würzburg, Germany), and was recorded and expressed as a percentage of the predicted value. Reference values from Zapletal et al. were used. ${ }^{22}$ Bronchial challenge tests were performed according to the dosimeter method. A calibrated DeVilbiss 646 nebulizer (DeVilbiss Health Care Inc, Somerset USA) and a Rosenthal dosimeter (Lab for Applied Immunology, Fairfax, USA) were used. PD20 was calculated by means of linear interpolation of the logarithmic dose-response curve. FENO was measured online according to guidelines from the European Respiratory Society (ERS) and the American Thoracic Society (ATS) using the NIOX analyzer (Aerocrine, Solna, Sweden). ${ }^{23,24}$ Patients performed three single breath manoeuvres online and the mean of these three measurements was recorded.

\section{Asthma control and medication use}

During all visits, asthma control was assessed using the 
M Kuethe et al.

original Dutch version of the Asthma Control Questionnaire (ACQ) developed by Juniper and colleagues ${ }^{25,26}$ (see Appendix 1 available online at www.thepcrj.org). Patients recalled their asthma-related experiences during the previous week and responded to each of 6 questions using a 7-point scale that ranges from 0 (well controlled) to 6 (extremely poorly controlled). The ACQ was dichotomised to identify patients whose asthma was well or not well controlled. To be confident that patients had well controlled asthma, the optimal and validated cut-off point was 0.75 (mean score of six items). ${ }^{27}$ Six additional questions were asked concerning planned and unplanned clinic visits, use of oral prednisolone, hospitalisations, absence from school and parental absence from work in the previous six months (see Appendix 2 available online at www.thepcrj.org). Exacerbations were defined as a requirement for a course of oral prednisolone.

\section{Medication}

All children were using ICS at entry to the study. The brand name of the ICS, the amount per dose, and the number of doses per day, were recorded during all visits. An adjusted daily dose of ICS was calculated based on prescribed medication. The use of combined LABA/ICS inhalers was recorded, as well as all other asthma and allergy medication including leukotriene receptor antagonists (LTRAs), antihistamines, nasal steroids and rescue medication.

\section{Statistical analysis}

Statistical analysis was performed using SPSS (version 14.0.1, Chicago, USA). The primary outcome variable $\mathrm{PD}_{20}$ was analysed after $\log _{2}$-transformation so that effects could be expressed in doubling dose (DD) units. As the PD20-values were right-censored for a large proportion of subjects (> $40 \%$ ), we used a censored regression analysis. Along with the treatment group (three groups represented by two dummy variables) we entered the following baseline covariates in the regression model: the stratum from which the subjects were derived (either general or hospital practice); age; gender; height; and the baseline measurement of $\mathrm{PD}_{20}$ combined with an indicator variable when $\mathrm{PD}_{20}$ exceeded the maximum dose without reaching a $20 \%$ decrease in FEV 1 . Noninferiority of care by the asthma nurse was accepted at a $5 \%$

Figure 1. Consort diagram of recruitment and randomization of subjects.

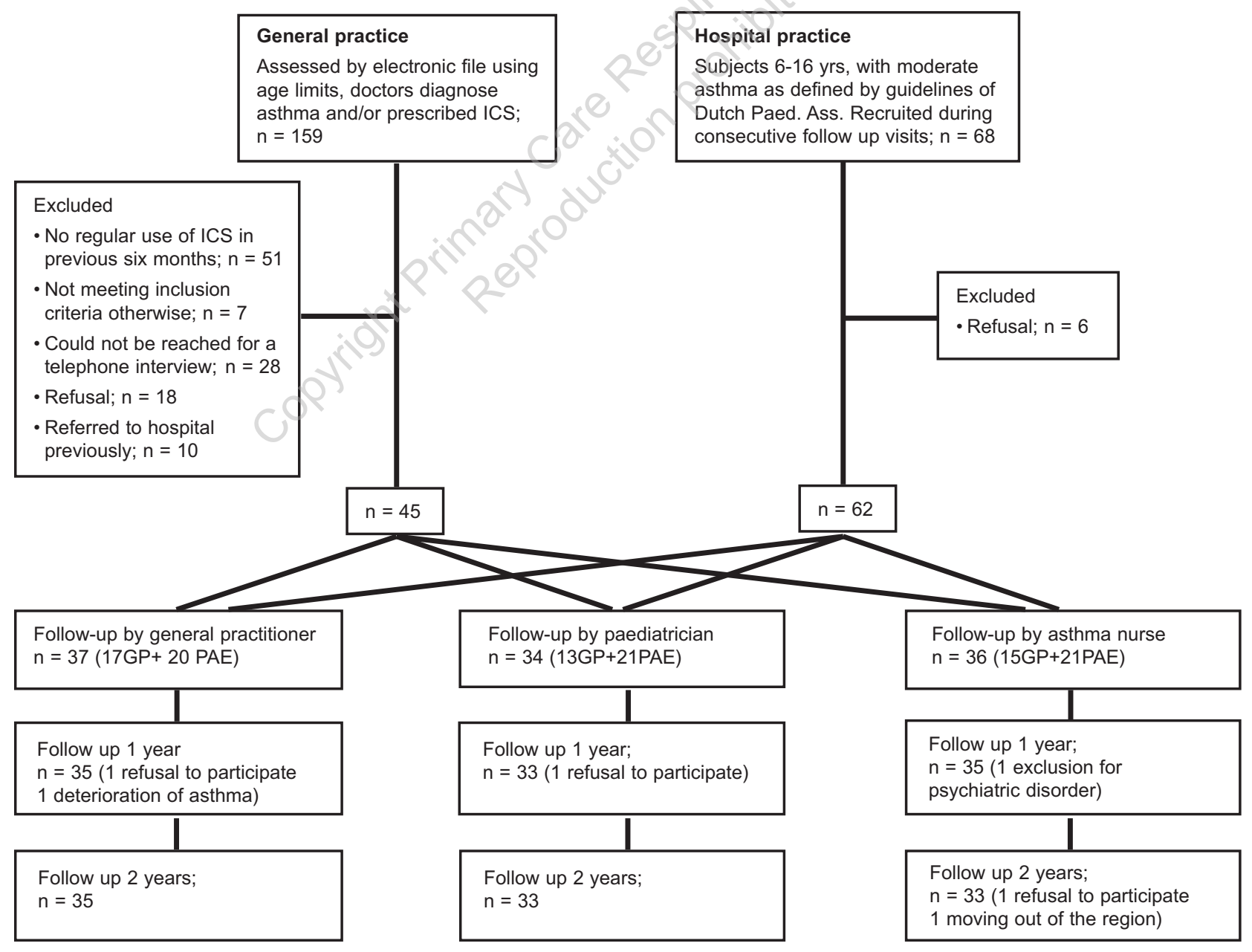


level, if the lower limit of the $90 \%$ confidence interval for the mean difference in PD$_{20}$ between the nurse practitioner on one hand and the GP or paediatrician on the other hand was larger than -1 DD.

The continuous outcome variables ( $\mathrm{FEV}_{1} \%$ predicted, FENO, ACQ-score and ICS-corrected dose LABA/ICS) were analysed using mixed model ANOVA for both visits 2 and 3 simultaneously. The dichotomous outcome variables ('yes' or 'no' regarding prescription of LABA/ICS, and 'yes' or 'no' regarding planned or unplanned visits) were analysed using logistic regression for visits 2 and 3 separately. The main explanatory variable is the treatment group. The following baseline covariates were entered along with treatment: the baseline measurement of the outcome variable at hand; stratum; age; gender; and height.

Prior to analysis, FENO was log-transformed because of its tendency to be positively skewed. The estimated confidence limits of the treatment effects on FENO were first backtransformed to percent differences between the geometric means of the treatment groups. Next, these percent differences were applied to the geometric mean in the ANgroup and then expressed as confidence limits of additive differences in FENO between the AN-group on one hand and the other two treatment groups on the other hand. Similarly for the logistic regression results, the estimated confidence limits of the treatment odds ratios were applied to the odds in the AN-group and then back-transformed to confidence limits of additive differences in percent points.

\section{Results}

\section{General characteristics}

107 children were randomised, 45 from general practice and 62 from hospital practice (Figure 1). Patient characteristics for the three follow-up arms are outlined in Table 1. Except for a slightly higher percentage of girls in the GP group, baseline characteristics did not differ between the groups. During follow-up, six children dropped out and four were lost to follow-up in the first year - three because of unwillingness to participate further and one because of unstable asthma. Two were lost to follow-up during the second year - one because of a psychiatric disorder unrelated to asthma and one because of geographic re-location. Withdrawals did not differ significantly between follow-up arms $(p=0.78)$.

\section{Lung function tests}

After 1 and 2 years, the difference in PD20 between the ANgroup and GP-group was $0.12(90 \% \mathrm{Cl}:-0.79 ; 1.02)$ and 0.75 $(90 \% \mathrm{Cl}:-0.33 ; 1.82)$ doubling dose, respectively, and between the AN-group and PP-group $-0.04(90 \% \mathrm{Cl}$ : $-0.90 ; 0.82)$ and $0.10(90 \% \mathrm{Cl}:-0.95 ; 1.16)$, respectively (see Table 2). Likewise, after one or two years of follow-up, no significant differences were evident in $\mathrm{FEV}_{1}$, airway hyperresponsiveness or exhaled FENO between the three follow-up arms (see Tables 2 and 3).

\section{Asthma Control}

ACQ score showed an almost significant overall treatment effect $(p=0.060)$ at the one-year visit and does not seem to support equivalence at that visit. However, considering the

Table 1. Patient characteristics at randomisation by follow-up arm. Values are means (SD), geometric means (IQR) or medians (IQR).

\begin{tabular}{|c|c|c|c|}
\hline Baseline Characteristics & General Practice & Paediatric Practice & Asthma Nurse \\
\hline Age (yrs) & $11.2(2.5)$ & $10.1(2.6)$ & $11.2(2.9)$ \\
\hline Atopy (\%) * & 69.0 & 72.7 & 83.3 \\
\hline $\begin{array}{l}\text { Lung function } \\
\mathrm{FEV}_{1} \text { (\% of predicted) } \\
\mathrm{FE}_{\mathrm{NO}} \text { (p.p.b) }\end{array}$ & $\begin{array}{l}105.9(14.7) \\
17.5(9.7-26.6) \\
\end{array}$ & $\begin{array}{l}103.8(16.3) \\
19.4(8.1-40.8) \\
\end{array}$ & $\begin{array}{l}101.2(14.4) \\
20.9(11.3-35) \\
\end{array}$ \\
\hline $\begin{array}{l}\text { Asthma Control } \\
\text { A.C.Q. }\end{array}$ & $0.50(0.17-1.67)$ & $0.83(0.17-1.00)$ & $0.67(0.17-1.33)$ \\
\hline $\begin{array}{l}\text { Additional Questions } \\
\text { Planned visits during previous } 6 \text { months (\%) } \\
\text { Unplanned visits during previous } 6 \text { months (\%) }\end{array}$ & $\begin{array}{l}64.9 \\
35.1\end{array}$ & $\begin{array}{l}73.5 \\
26.5\end{array}$ & $\begin{array}{l}62.9 \\
27.8\end{array}$ \\
\hline
\end{tabular}


M Kuethe et al.

Table 2. Geometric mean $\mathrm{PD}_{20}$ at baseline, visit I\&II in three study arms and comparison of efficacy between asthma nurse-general practitioner and asthma nurse-paediatrician for $\mathrm{PD}_{20}$. P-values and point and interval estimates of the difference between treatments were obtained from the models used.

\begin{tabular}{|c|c|c|c|c|c|c|}
\hline & \multicolumn{3}{|c|}{ 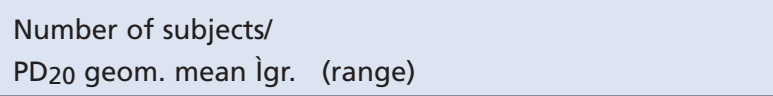 } & \multicolumn{2}{|c|}{ Efficacy ( $90 \% \mathrm{Cl}$ in DD units) } & \multirow[t]{2}{*}{$\mathrm{P}$ value +} \\
\hline & GP & PP & AN & $A N-G P$ & $A N-P P$ & \\
\hline Baseline* & $\begin{array}{l}36 \\
532(37.5 ;>1570)\end{array}$ & $\begin{array}{l}34 \\
310(13.0 ;>1570)\end{array}$ & $\begin{array}{l}35 \\
295(13.8 ;>1570)\end{array}$ & & & \\
\hline Visit $\|^{* *}$ & $\begin{array}{l}33 \\
562(17.0 ;>1570)\end{array}$ & $\begin{array}{l}33 \\
344(9.9 ;>1570)\end{array}$ & $\begin{array}{l}34 \\
320(20.0 ;>1570)\end{array}$ & $\begin{array}{l}0.12 \\
(-0.79 \text { to }+1.02)\end{array}$ & $\begin{array}{l}-0.04 \\
(-0.90 \text { to }+0.82)\end{array}$ & 0.96 \\
\hline Visit III*** & 34 & 32 & 32 & 0.75 & 0.10 & 0.55 \\
\hline & $459(11.5 ;>1570)$ & $351(11.0 ;>1570)$ & $356(6.0 ;>1570)$ & $(-0.33$ to +1.82$)$ & $(-0.95$ to +1.16$)$ & \\
\hline
\end{tabular}

$+\mathrm{H}_{0}=$ no treatment effect., $* 2$ missing, ** 7 missing, *** 9 missing.

Table 3. Lung function and asthma control status for the three follow-up arms at 1 - and 2-years follow up. Data are expressed as mean (SD), geometric mean (IQR) or median (IQR). P-values and point and interval estimates of the difference between treatments were obtained from the models used.

\begin{tabular}{|c|c|c|c|c|c|c|c|}
\hline & yrs & $\begin{array}{l}\text { General } \\
\text { Practice (GP) }\end{array}$ & $\begin{array}{l}\text { Paediatric } \\
\text { Practice (PP) }\end{array}$ & $\begin{array}{l}\text { Asthma } \\
\text { Nurse (AN) }\end{array}$ & $P$ & $\begin{array}{l}90 \% \mathrm{Cl} \\
(\mathrm{AN}-\mathrm{GP})\end{array}$ & $\begin{array}{l}90 \% \mathrm{Cl} \\
(\mathrm{AN}-\mathrm{PP})\end{array}$ \\
\hline \multicolumn{8}{|l|}{ Lung function } \\
\hline \multirow{4}{*}{$\begin{array}{l}\mathrm{FEV}_{1} \\
(\% \text { predicted })\end{array}$} & 1 & 105.2 & 103.1 & 101.2 & 0.29 & 3.6 & 0.5 \\
\hline & & (15.8) & (15.0) & $(14.4)$ & & $(-0.2$ to 7.5$)$ & $(-3.3$ to 4.3$)$ \\
\hline & 2 & 107.0 & 103.5 & 102.0 & 0.57 & 2.5 & 0.9 \\
\hline & & $(14.0)$ & $(15.2)$ & (14.6) & & $(-1.1$ to 6.2$)$ & $(-2.7$ to 4.5$)$ \\
\hline \multirow[t]{4}{*}{$\mathrm{FE}_{\mathrm{NO}}$ (p.p.b) } & 1 & 16.4 & 13.9 & 15.3 & 0.44 & -2.5 & 1.6 \\
\hline & & $(7.4-35.7)$ & $(5.4-38.4)$ & $(9-24.8)$ & & (-6.6 to 3.4$)$ & $(-2.8$ to 7.8$)$ \\
\hline & 2 & 22.1 & $22.4 \bigcirc$ & 17.4 & 0.36 & -5.1 & -2.9 \\
\hline & & $(11.7-50.4)$ & $(12.1-46.3)$ & $(10.3-26.8)$ & & $(-9.4$ to 0.9$)$ & $(-8.2$ to 3.5$)$ \\
\hline \multicolumn{8}{|l|}{ Asthma control } \\
\hline \multirow[t]{4}{*}{ A.C.Q. } & 1 & 0.50 & 0.17 & 0.50 & 0.060 & -0.22 & 0.18 \\
\hline & & $(0.00-1.50)$ & $(0.00-0.75)$ & $(0.00-1.17)$ & & $(-0.49$ to 0.05$)$ & $(-0.09$ to 0.45$)$ \\
\hline & 2 & 0.33 & 0.33 & 0.33 & 0.88 & -0.03 & 0.04 \\
\hline & & $(0.00-0.67)$ & $(0.08-1.00)$ & $(0.00-0.67)$ & & $(-0.26$ to 0.20$)$ & $(-0.19$ to 0.27$)$ \\
\hline \multirow{4}{*}{$\begin{array}{l}\text { Planned visits during } \\
\text { previous } 6 \text { months (\%) }\end{array}$} & 1 & 45.7 & 87.9 & 94.3 & $<0.0005$ & 49.7 & 6.0 \\
\hline & & & & & & (39.2 to 92.7 ) & (0.1 to 74.4 ) \\
\hline & 2 & 26.5 & 87.9 & 75.8 & $<0.0005$ & 56.2 & -5.0 \\
\hline & & & & & & (34 to 68.8 ) & $(-18.4$ to 17.5$)$ \\
\hline \multirow{4}{*}{$\begin{array}{l}\text { Unplanned visits during } \\
\text { previous } 6 \text { months (\%) }\end{array}$} & 1 & 28.6 & 21.2 & 22.9 & 0.84 & -3.7 & \\
\hline & & & & & & (-26.1 to 10.7$)$ & $(-20.3$ to 13.8$)$ \\
\hline & 2 & 20 & 15.2 & 15.2 & 0.84 & -1.0 & 0.1 \\
\hline & & & & & & (-22.7 to 9.4$)$ & $(-21.8$ to 10.1$)$ \\
\hline \multirow{5}{*}{$\begin{array}{l}\text { Medication } \\
\text { ICS corrected day } \\
\text { dose. (l̀gr) }\end{array}$} & & & & & & & \\
\hline & 1 & 275 & 279 & 277 & 0.88 & & 6 \\
\hline & & (143) & (171) & $(200)$ & & $(-43$ to 79$)$ & (-56 to 67$)$ \\
\hline & 2 & 245 & 249 & 238 & 0.99 & 5 & 7 \\
\hline & & (220) & (177) & (177) & & $(-7.1$ to 80$)$ & $(-68$ to 82$)$ \\
\hline \multirow[t]{4}{*}{ (\%)prescribed LABA/ICS } & 1 & 17.1 & 15.2 & 20 & 0.90 & 3.6 & 6 \\
\hline & & & & & & $(-15.8$ to 13.8$)$ & $(-17.0$ to 13.9$)$ \\
\hline & 2 & 14.3 & 12.1 & 18.2 & 0.74 & 5.6 & 5.3 \\
\hline & & & & & & $(-12.9$ to 14.4$)$ & $(-13.9$ to 14.4$)$ \\
\hline
\end{tabular}


Table 4. Consultations with the asthma nurse and the paediatrician, for the study period of $\mathbf{2}$ years.

\begin{tabular}{lll} 
Nr of consultations & Nr of subjects & $(\%)$ \\
\hline 0 & 21 & 58.3 \\
\hline 1 & 7 & 19.4 \\
\hline 2 & 5 & 13.9 \\
\hline 4 & 1 & 2.7 \\
\hline 6 & 1 & 2.7 \\
\hline 9 & 1 & 2.7
\end{tabular}

paired comparisons it appeared that only between the GPgroup and the PP-group was a significant difference found $(p=0.018)$ while both the GP-group and the PP-group did not significantly differ from the AN-group ( $p$-values 0.18 and 0.28 , respectively). Considering changes from baseline using a similar mixed model, a significant decrement in ACQ-score was only seen in the PP-group at both visits ( $p$-values 0.032 and 0.048 , respectively).

There were no differences between groups regarding the number of severe exacerbations as expressed by the number of prednisolone courses. In the groups as a whole, few exacerbations occurred: five (one in the GP-group, one in the PPgroup and three in the AN-group) and two ( one in the GP-group and one in the PP-group) in the first and second year, respectively, compared to nine in the six months prior to the start of the study. There were no hospital admissions during the course of the study.

A marked difference was found in the percentage of children who had regular follow-up visits at one year $45.7 \%$ of children were regularly followed up in general practice versus $87.9 \%$ in paediatric practice and $94.3 \%$ in the AN-group ( $\mathrm{p} \leq 0.0005)$. After two years' follow-up these percentages were $26.5 \%$, $87.9 \%$ and $75.8 \%$, respectively $(p \leq 0.0005)$. No significant differences were found in the percentage of unplanned visits. Absence from school for one or more days as well as parental absence from work was not significantly different between groups during all consecutive visits (Table 3).

\section{Medication}

The corrected daily dose (busesonide equivalence) of ICS as well as the percentage of children who were prescribed LABAIICS was not significantly different between groups at both follow-up visits. After one year of follow-up, two children in the PP-group and two children in the AN-group stopped regular use of ICS. After two years of follow-up, seven children in the GPgroup, five children in the PP-group and five children of the ANgroup subjects, had stopped regular use of ICS.

Consultation with the paediatrician by the hospitalbased asthma nurse

In $58 \%(n=21)$ of the AN-group subjects, the asthma nurse was confident to provide asthma management without support from a paediatrician. In $34 \%(n=12)$, one or two short oral communications took place to assist the nurse with management (see Table 4). Only three subjects ( $8 \%$ of children in the AN-group) had problems that required more frequent input from the paediatrician (Table 4).

\section{Discussion}

In this prospective randomised controlled follow-up study we have shown that paediatric asthma care provided by a hospitalbased specialised asthma nurse is not inferior to that provided by a GP or a paediatrician in children with stable asthma aged 6 to 16 years. Lung function parameters and asthma control parameters such as ACQ, exacerbations, and school absence, did not differ between the groups.

The only difference we observed was that children in the general practice group had significantly fewer planned followup visits in comparison with the paediatrician group and the asthma nurse group. Nonetheless, this lower frequency of review did not result in worsening of asthma control or of any other asthma parameters in the general practice group during the two-year follow-up period. Our results demonstrate that children with stable asthma can be managed by a GP or asthma nurse enabling paediatricians to focus on those children with unstable or severe asthma.

Although not the primary outcome measure of this study, these results suggest also that a lower follow-up frequency in children with stable disease is not harmful. It is not known from the literature what the ideal frequency of follow-up visits should be. From an economic point of view it may be useful to investigate the optimal follow-up frequency to maintain good asthma control in this stable group. Diette et al. showed that physicians working in primary care did not comply equally well with asthma guidelines compared to physicians working in secondary care. ${ }^{28}$ However, this study did not encompass parameters that are directly related to asthma control such as ACQ, exacerbations and lung function. We showed in an earlier paper $^{29}$ a small but statistically significant difference in ACQ between children treated in primary care and in hospital care, whereas all the other measured parameters showed no statistically significant difference. Publications by Kelly et al. ${ }^{30}$ and Bratava et al. ${ }^{31}$ slightly favour specialist care over primary care. However, the populations and health care settings in these studies differ considerably from the Dutch situation. In the study by Kelly and colleagues, children aged 2 to 15 were recruited from a Medicaid insured group (a US insurance scheme for lowincome people) and these children were randomised to a tertiary care paediatric allergy clinic versus primary care. ${ }^{30}$ Bratava and colleagues showed in a meta-analysis that self management programs favour quality improvement in 
general - but there were multiple strategies used in the different studies. ${ }^{31}$

Our findings - that asthma management provided by a hospital-based specialised asthma nurse is not inferior to management provided by a GP or a paediatrician - agrees with the earlier findings of Kamps et al. ${ }^{16}$ This may have important implications for the organisation of paediatric outpatient care. First, nurse-led outpatient management can be provided at a lower cost than medical care by a paediatrician. ${ }^{32}$ Second, it frequently happens in daily practice that acute cases and concerns take priority over the less urgent need to bring chronic illness under optimal management; Bodenheimer et al. call this "the tyranny of the urgent" ${ }^{13}$ Separating chronic care from acute and urgent care in an organisation is a major step in optimising the management of chronic illness. ${ }^{15}$ In paediatric outpatient practice this can be solved by appointing specialised asthma nurses for the care of chronic illnesses like asthma.

Obviously there are a number of prerequisites to this proposal. The patient should have stable and well controlled asthma. The asthma nurse should work strictly according to guidelines. There should be a low threshold for consulting with a paediatrician or a GP when a patient deteriorates or shows unexpected symptoms. Supervision or revision by the paediatrician or GP should always take place when the asthma nurse is uncertain about the child's management. Ultimately, the final responsibility remains in the hands of the supervising physician. In our study setting we fulfilled these conditions and demonstrated that the asthma nurse could work relatively independently and only needed the assistance of the supervising paediatrician in a minority of cases. Furthermore, delegation of care relieves the workload of the physician which is important, because this is often a barrier to provision of optimal care for chronic illness.

Our study has a number of limitations. At first, due to the character of the study, blinding was practically impossible. To what extent this may have induced bias is hard to say. A further limitation was that for recruitment and follow-up of children in the general practice group we had to depend on GPs who were enthusiastic about participating in research concerning respiratory care in children. An unselected sample of subjects recruited from an unselected sample of general practices was not practically feasible. This might have caused bias in that the results in our general practice group may have been more favourable than those in an unselected sample of GPs. One could argue that we should have included symptom scores recorded in diaries to measure asthma control status. However, since reliable recording in a study of two years' duration is not feasible we elected instead to use the ACQ, an acknowledged reliable measure of asthma control. ${ }^{27}$

In most hospitals the role of the specialised asthma nurse is complementary to that of the physician. Our results, and those of others, ${ }^{16,17}$ show that the asthma nurse can provide longterm management of asthma in children with well controlled asthma. Kamps' study ${ }^{16}$ was confined to a hospital setting. Our study included the primary care setting in the comparison of care. Therefore, we conclude that our findings are applicable in secondary as well as in primary care, provided that the same conditions are met.

In conclusion, we have demonstrated that the efficacy of specialised asthma nurse care in the outpatient management of stable childhood asthma is not inferior to traditional management by paediatricians or GPs. Furthermore, the results of our study suggest that a low follow-up frequency does not detract from maintenance of good disease control in children with stable asthma.

\section{Acknowledgements}

The following general practitioners actively contributed to this research: AC Poppelaars, RA Dingjan, JCG Corten, CJM Beukers, J Snobl, PAM van Hellenberg Hubar, CJJ van der Schelling van der Zwet, NCJ Wisse, HJ Weltevrede, POEM Lutken, MEJM van Teefelen, HLPAM van Valkenburg, JA Oudraad, B Nikkels, AFM Veenman, HAM Haverkamp, FPC de Beer, HAJM Gabriëls.

S.Suelmann and J.Matthijssen performed lung function testing and all other data acquisition.

Professor N. Walsh (Dept of Pathology, Dalhousie University, Halifax, Canada) critically reviewed the manuscript.

\section{References}

1. Wenzel SE, Covar R. Update in asthma 2005. Am J Respir Crit Care Med 2006;173(7):698-706. http://dx.doi.org/10.1164/rccm.2601007

2. British Guideline on the Management of Asthma. Thorax 2008;63(Suppl 4):iv1 -121. http://dx.doi.org/10.1136/thx.2008.097741

3. Levy ML, Thomas M, Small I, Pearce L, Pinnock H, Stephenson P. Summary of the 2008 BTS/SIGN British Guideline on the management of asthma. Prim Care Respir J 2009;18(Suppl1):S1-16. http://dx.doi.org/10.3132/pcrj.2008.00067

4. Duiverman EJ, Jobsis Q, van Essen-Zandvliet EE, et al. [Guideline 'Treating asthma in children' for pediatric pulmonologists (2nd revised edition). I. Diagnosis and prevention]. Ned Tijdschr Geneeskd 2003;147(39):1905-08.

5. Duiverman EJ, Brackel HJ, Merkus PJ, et al. [Guideline 'Treating asthma in children' for pediatric pulmonologists (2nd revised edition). II. Medical treatment]. Ned Tijdschr Geneeskd 2003;147(39):1909-13.

6. van Essen-Zandvliet EE, Hughes MD, Waalkens HJ, et al. Effects of 22 months of treatment with inhaled corticosteroids and/or beta-2-agonists on lung function, airway responsiveness, and symptoms in children with asthma. The Dutch Chronic Non-specific Lung Disease Study Group. Am Rev Respir Dis 1992;146(3):547-54.

7. van Essen-Zandvliet EE, Hughes MD, Waalkens HJ, et al. Remission of childhood asthma after long-term treatment with an inhaled corticosteroid (budesonide): can it be achieved? Dutch CNSLD Study Group. Eur Respir J 1994;7(1):63-8. http://dx.doi.org/10.1183/09031936.94.07010063

8. Global Strategy for Asthma Management and Prevention (revised 2008): Global Initiative for asthma (GINA). NHLG available at www ginasthma com 2008.

9. Guarnaccia S, Lombardi A, Gaffurini A, et al. Application and implementation of the GINA asthma guidelines by specialist and primary care physicians: a longitudinal follow-up study on 264 children. Prim Care Respir J 2007;16(6):357-62. http://dx.doi.org/10.3132/pcrj.2007.00077

10. O'Byrne PM. Asthma Management Guidelines: the issue of implementation. Prim Care Respir J 2006;15(1):5-6. http://dx.doi.org/10.1016/j.pcrj.2005.11.005 
11. Akinbami LJ, Moorman JE, Garbe PL, et al. Status of childhood asthma in the United States, 1980-2007. Pediatrics 2009;123(Suppl3):S131-45. http://dx.doi.org/10.1542/peds.2008-2233C

12. van Schayck CP, Smit HA. The prevalence of asthma in children: a reversing trend. Eur Respir J 2005;26(4):647-50. http://dx.doi.org/10.1183/ 09031936.05 .00019805

13. Bodenheimer $T$, Wagner $E H$, Grumbach $K$. Improving primary care for patients with chronic illness. JAMA 2002;288(14):1775-9.

14. Bodenheimer T, Wagner EH, Grumbach K. Improving primary care for patients with chronic illness: the chronic care model, Part 2. JAMA 2002;288(15):1909 $-14$.

15. Tsai AC, Morton SC, Mangione CM, et al. A meta-analysis of interventions to improve care for chronic illnesses. Am J Manag Care 2005;11(8):478-88.

16. Kamps AW, Brand PL, Kimpen JL, et al. Outpatient management of childhood asthma by paediatrician or asthma nurse: randomised controlled study with one year follow up. Thorax 2003;58(11):968-73. http://dx.doi.org/ 10.1136/thorax.58.11.968

17. Nathan JA, Pearce L, Field C, et al. A randomized controlled trial of follow-up of patients discharged from the hospital following acute asthma: best performed by specialist nurse or doctor? Chest 2006;130(1):51-7. http://dx.doi.org/10.1378/chest.130.1.51

18. Bindels PJE, Van der Wouden JC, Ponsioen BP et al. NHG Standaard Asthma bij kinderen. Huisarts en Wetenschap 2006;49(11):130-43.

19. Sont JK, Willems LN, Bel EH, et al. Clinical control and histopathologic outcome of asthma when using airway hyperresponsiveness as an additional guide to long-term treatment. The AMPUL Study Group. Am J Respir Crit Care Med 1999;159(4 Pt 1):1043-51.

20. Grol MH, Postma DS, Vonk JM, et al. Risk factors from childhood to adulthood for bronchial responsiveness at age 32-42 yr. Am J Respir Crit Care Med 1999;160(1):150-6.

21. Verberne AA, Frost C, Roorda RJ, et al. One year treatment with salmeterol compared with beclomethasone in children with asthma. The Dutch Paediatric Asthma Study Group. Am J Respir Crit Care Med 1997;156(3 Pt 1):688-95.
22. Zaptelal A, Samanek M, Paul T. Lungfunction in children and adolescents: methods, reference values. Prog Respir Res 1987;22:114-218.

23. Baraldi $E$, de Jongste JC. Measurement of exhaled nitric oxide in children, 2001. Eur Respir J 2002;20(1):223-37. http://dx.doi.org/10.1183/09031936.02.00293102

24. ATS/ERS recommendations for standardized procedures for the online and offline measurement of exhaled lower respiratory nitric oxide and nasal nitric oxide, 2005. Am J Respir Crit Care Med 2005;171(8):912-30. http://dx.doi.org/10.1164/rccm.200406-710ST

25. Juniper EF, O'Byrne PM, Guyatt, et al. Development and validation of a questionnaire to measure asthma control. Eur Respir J 1999;14(4):902-07. http://dx.doi.org/10.1034/j.1399-3003.1999.14d29.x

26. Juniper EF, Svensson K, Mork AC, et al. Measurement properties and interpretation of three shortened versions of the asthma control questionnaire. Respir Med 2005;99(5):553-8. http://dx.doi.org/10.1016/j.rmed.2004.10.008

27. Juniper EF, Bousquet J, Abetz L, et al. Identifying 'well-controlled' and 'not wellcontrolled' asthma using the Asthma Control Questionnaire. Respir Med 2006;100(4):616-21. http://dx.doi.org/10.1016/j.rmed.2005.08.012

28. Diette GB, Skinner EA, Nguyen TT, et al. Comparison of quality of care by specialist and generalist physicians as usual source of asthma care for children. Pediatrics 2001;108(2):432-7. http://dx.doi.org/10.1542/peds.108.2.432

29. Kuethe MC, Vaessen-Verberne AA, Bindels PJ, et al. Children with asthma on inhaled corticosteroids managed in general practice or by hospital paediatricians; is there a difference? Prim Care Respir J 2010;19(1):62-7. http://dx.doi.org/10.4104/pcrj.2009.00063

30. Kelly CS, Morrow AL, Shults J, et al. Outcomes evaluation of a comprehensive intervention program for asthmatic children enrolled in madicaid. Paediatrics 2000;105(5):1029-35. http://dx.doi.org/10.1542/peds.105.5.1029

31. Bratava DM, Gienger AL, Holty JE, et al. Quality improvement stategies for children with asthma: a systematic review. Arch Pediatr Adolesc Med 2009; 163(6):572-81. http://dx.doi.org/10.1001/archpediatrics.2009.63

32. Kamps AW, Roorda RJ, Kimpen JL, et al. Impact of nurse-led outpatient management of children with asthma on healthcare resource utilisation and costs. Eur Respir $J$ 2004;23(2):304-09. http://dx.doi.org/10.1183/09031936.03.00052203 
M Kuethe et al.

Appendix 1. Dutch asthma control questionnaire

\section{TRAM Visit III}

P.i.d.

$\ldots \ldots \ldots$

Achternaam

Voorvoegsel(s)

Voornaam

Geboortedatum

$\ldots . . . . . / \ldots$

Patiëntennummer 
Nurse led outpatient care in paediatric asthma

\begin{tabular}{|c|c|c|}
\hline Question & No / Yes & $\mathrm{Nr}$ \\
\hline $\begin{array}{l}\text { 1. How many regular follow up appointments with the general practitioner, paediatrician or } \\
\text { asthma nurse took place during the past six months? }\end{array}$ & & $\begin{array}{l}\ldots \text { GP } \\
\ldots \text { PAED } \\
\ldots \text { AN }\end{array}$ \\
\hline $\begin{array}{l}\text { 2. How many unplanned appointments with the general practitioner, paediatrician or asthma } \\
\text { nurse took place during the past six months? }\end{array}$ & & $\begin{array}{l}\ldots \text { GP } \\
\ldots \text { PAED } \\
\ldots \text { AN }\end{array}$ \\
\hline 3.Was one or more courses of prednisone prescribed during the past six months & $N / Y$ & $\begin{array}{l}\ldots \text { GP } \\
\ldots \text { PAED } \\
\ldots \text { AN } \\
\end{array}$ \\
\hline 4. Were there one or more hospital admissions due to asthma during the past six months? & $=N / Y$ & $\ldots \ldots \ldots$ \\
\hline 5. Was there absence from school due to asthma during the last six months? & $N / Y$ & .... days \\
\hline 6. Was there parental absence from work due to asthma of son or daughter during the last six months? & $N / Y$ & .... days \\
\hline
\end{tabular}

